\title{
Saturation sampling for spatial variation in multiple air pollutants across an inversion-prone metropolitan area of complex terrain
}

Jessie LC Shmool ${ }^{*}$, Drew R Michanowicz ${ }^{1}$, Leah Cambal', Brett Tunno ${ }^{1}$, Jeffery Howell ${ }^{1}$, Sara Gillooly ${ }^{1}$, Courtney Roper', Sheila Tripathy', Lauren G Chubb', Holger M Eisl ${ }^{2}$, John E Gorczynski², Fernando E Holguin ${ }^{3}$, Kyra Naumoff Shields ${ }^{1}$ and Jane E Clougherty ${ }^{1}$

\begin{abstract}
Background: Characterizing intra-urban variation in air quality is important for epidemiological investigation of health outcomes and disparities. To date, however, few studies have been designed to capture spatial variation during select hours of the day, or to examine the roles of meteorology and complex terrain in shaping intra-urban exposure gradients.

Methods: We designed a spatial saturation monitoring study to target local air pollution sources, and to understand the role of topography and temperature inversions on fine-scale pollution variation by systematically allocating sampling locations across gradients in key local emissions sources (vehicle traffic, industrial facilities) and topography (elevation) in the Pittsburgh area. Street-level integrated samples of fine particulate matter $\left(\mathrm{PM}_{2.5}\right)$, black carbon (BC), nitrogen dioxide $\left(\mathrm{NO}_{2}\right)$, sulfur dioxide $\left(\mathrm{SO}_{2}\right)$, and ozone $\left(\mathrm{O}_{3}\right)$ were collected during morning rush and probable inversion hours (6-11 AM), during summer and winter. We hypothesized that pollution concentrations would be: 1) higher under inversion conditions, 2) exacerbated in lower-elevation areas, and 3) vary by season.
\end{abstract}

Results: During July - August 2011 and January - March 2012, we observed wide spatial and seasonal variability in pollution concentrations, exceeding the range measured at regulatory monitors. We identified elevated concentrations of multiple pollutants at lower-elevation sites, and a positive association between inversion frequency and $\mathrm{NO}_{2}$ concentration. We examined temporal adjustment methods for deriving seasonal concentration estimates, and found that the appropriate reference temporal trend differs between pollutants.

Conclusions: Our time-stratified spatial saturation approach found some evidence for modification of inversion-concentration relationships by topography, and provided useful insights for refining and interpreting GIS-based pollution source indicators for Land Use Regression modeling.

Keywords: Air pollution monitoring, Black carbon (BC), Fine particulate matter (PM 2.5$)$, Airborne particles with a diameter of 2.5 micrometers or less, Geographic information systems (GIS), Nitrogen dioxide $\left(\mathrm{NO}_{2}\right)$, Spatial variability, Temperature inversion

\footnotetext{
* Correspondence: jlcarr@pitt.edu

${ }^{1}$ Department of Environmental and Occupational Health, University of

Pittsburgh Graduate School of Public Health, Pittsburgh, PA, USA

Full list of author information is available at the end of the article
} 


\section{Background}

Advances in intra-urban air monitoring, such as spatial saturation sampling and land use regression (LUR) modeling [1-8], have substantially improved epidemiological estimation of air pollution impacts on health in urban areas $[9,10]$. However, few studies have been designed to capture spatial variation during select hours of the day, and important challenges remain for incorporating timevarying meteorological factors and local topography into the assessment of fine-scale spatial variation in air quality $[11,12]$. The Pittsburgh metropolitan area represents an opportunity to extend air monitoring methods to address spatial and temporal drivers of air quality variability - specifically spatial confounding among multiple pollution sources (e.g., legacy industry, vehicle traffic), and potential modifiers of source-concentration relationships (e.g., elevation, temperature inversions) - toward better characterizing risk factors for multiple health outcomes, and growing regional health disparities $[13,14]$.

Spatial saturation monitoring and land use regression (LUR) modeling are standard exposure assessment methodologies for characterizing intra-urban variability in air pollution concentrations [1,4-6,11] and pollution source apportionment [15]. For spatial saturation studies, Geographic Information System (GIS)-based indicators of local air pollution sources are used to systematically allocate monitoring locations to saturate hypothesized pollution concentration gradients across complex domains. This spatially-informed study design enables estimation of fine-scale variation in air quality, and can generate chronic air pollution exposure assessments for environmental epidemiology.

Integrating primarily spatial (e.g., distribution of roadways and industrial facilities) and temporal (e.g., temperature, weather) factors that contribute to local air pollution, and understanding their potential interactions, is an important methodological challenge for LUR-based analysis. One common approach to disentangling spatial and temporal factors is designating 'reference', or 'background, monitors to, first, determine the proportion of local pollution explained by temporally-varying factors (e.g., meteorology, long-range transport) $[7,16]$, and, second, to adjust samples collected at different locations and points in time to indicate seasonally-representative concentrations. As such, siting reference monitors is important for robust study design; it is well established that locating monitors away from local source influence will produce more accurate measurements of temporally-mediated pollution patterns [17], but there is little guidance in the literature to help investigators target meteorological interactions with local topography, especially for chemically reactive or photochemically active pollutants (e.g., $\mathrm{NO}_{2}$ ). As more urban studies are monitoring multiple pollutants, for which the relative spatio-temporal components are different [18], the citing of reference monitors in a way that is interpretable for multiple pollutants and across topographic regimes is an important challenge.

Despite over two decades of air quality improvements following the decline of the steel industry in western Pennsylvania, the Pittsburgh metropolitan area exceeds national health-based air quality standards for criteria pollutants [19]. While high air pollution levels are partially attributable to regional transport of emissions from coal-fired power plants of the Ohio valley, local pollution sources are substantial drivers [20-22]. Local emissions inventories are dominated by a small number of remaining large industrial facilities strategically located along river valleys [19], including the nation's largest coke works, which sits approximately 24 kilometers south of downtown. A diverse transportation network of rail, barge, diesel trucks, and passenger vehicles contribute mobile emissions. Though a relatively small city (approximately 300,000 residents), urban sprawl and roadway vehicle congestion is a substantial problem, as a large number of tunnels and bridges lead to traffic bottlenecks, and some highway segments rank among the twenty most congested outside of Los Angeles and New York City [23]. Finally, population susceptibility factors (e.g., poor access to healthcare, concentrated poverty) are spatially patterned with topography and pollution sources, clustered in industrial river valleys, creating the potential for joint and synergistic health effects. In the City of Pittsburgh, for example, median household income is approximately $\$ 10,000$ less among census block groups in the $20^{\text {th }}$ percentile of elevation, as compared to highest-elevation $\left(80^{\text {th }}\right.$ percentile) census block groups [24].

In the Pittsburgh metropolitan area, complex topography at the confluence of three rivers combines with meteorology to drive frequent atmospheric temperature inversions [25], which can prevent vertical dispersion of airborne pollutants, trapping emissions near the earth's surface. Inversion layers form when the warm-to-cool vertical temperature gradient of the atmosphere is inverted, and are generally accompanied by low surface wind speeds. Causes of inversions are dependent upon local topography and meteorology interactions, including when rapid overnight cooling of the earth's surface causes cooling of air near the surface, compared to higher altitude air (i.e., radiative inversion), or when high pressure systems descend into relatively cooler low elevation areas (i.e., subsidence), both of which may occur in the Pittsburgh region. In areas of complex terrain, inversion effects on local air pollution may be exacerbated in low-lying areas and valleys, where the earth's surface is shadowed and slower to warm with the sunrise $[26,27]$. Inversions have been linked with acute pollution events of photochemical smog and particulate matter, 
such as occurred in nearby Donora, PA in 1948 [28], and have been linked with cardiovascular [29] and respiratory health $[30,31]$. In the pilot mobile monitoring study which informed the design of this campaign, we identified regional inversion conditions on $50 \%$ of summertime sampling days, and, accordingly, $\mathrm{PM}_{2.5}$ concentrations were greater during morning sampling hours (8-10 AM) than afternoon (12-2 PM) [32].

Here, we present a spatial saturation approach designed to capture the impact of inversion effects across complex terrain - towards evaluating the efficacy of topographic information for capturing potential modification of local source-concentration relationships by meteorology. We describe study design and implementation of a two-season (winter and summer) multi-pollutant monitoring campaign across the Pittsburgh metropolitan area, using programmable integrated monitors to sample solely during morning hours when atmospheric inversions are most frequent. We report GIS-based methods for systematically allocating monitors across locallyspecific pollution source and topography profiles, and address challenges of distinguishing spatial and temporal components of local pollution variation in different pollutants by comparing two temporal adjustment approaches. This is the first study, to our knowledge, to explicitly capture spatial variation in pollution during selected hours of the day - here, targeting topographymeteorology interactions by collecting spatially-distributed samples only during inversion-prone hours of the day, and including topography in monitoring site allocation. Air quality data derived from this study will ultimately be applied towards: (a) LUR modeling of intra-urban variability in multiple pollutants and seasons, and (b) epidemiologic investigation of health outcomes.

\section{Methods}

We used GIS-based indicators of local pollution sources and topography to systematically allocate 36 air monitoring sites across the metropolitan area during two seasons June-August 2011 (summer) and January-March 2012 (winter). The same sites were repeated in each season, within which monitors were distributed between six 5-day weekday sessions in each season. We collected integrated samples of criteria pollutants, and derived seasonal averages using two reference monitors - one urban and one regional background. We tested the hypothesis that lower-elevation areas may experience higher pollution concentrations under inversion conditions [20,32], and that these effects may vary by season.

\section{Sampling instrumentation and laboratory analyses}

We collected integrated samples of nitrogen dioxide $\left(\mathrm{NO}_{2}\right)$, ozone $\left(\mathrm{O}_{3}\right)$, sulfur dioxide $\left(\mathrm{SO}_{2}\right)$, fine particulate matter $\left(\mathrm{PM}_{2.5}\right)$ black carbon $(\mathrm{BC})$, and constituents using portable ambient air sampling units originally designed for the New York City Community Air Survey [7]. Particle sampling instruments include a Dual Stage $\mathrm{PM}_{2.5}$ Harvard Impactor (Air Diagnostics and Engineering Inc.) with particulate matter collected onto $37 \mathrm{~mm}$ Teflon filters (PTFE membrane, $2 \mu \mathrm{m}$ pores, Pall Life Sciences), a HOBO data logger for relative humidity, temperature, and barometric pressure readings (Onset Computer Corporation). Battery-operated vacuum pumps (SKC, Inc.) moved ambient air through particle filters at a constant rate of 4 liters per minute, and pre - and postflow rates were recorded for data quality assurance. Passive gaseous samplers (Ogawa \& Co. USA) were placed into weather tight shelters on the exterior of sampling units. Sampling instruments were housed in weather tight boxes, and mounted 3-4 meters above ground on utility poles, near the breathing zone.

$\mathrm{PM}_{2.5}$ and $\mathrm{BC}$ were measured solely during weekday morning rush hours and potential inversion hours, using a chrontroller (ChronTrol Corporation) to program the sampling units to simultaneously sample all locations (including reference sites) each weekday (Monday-Friday) from 6:00 AM to 11:00 AM. Deployment and retrieval schedules were aimed at minimizing differences in exposed time for passive badges between monitors and across sessions.

Teflon filters were pre- and post-weighed at the University of Pittsburgh, Department of Environmental \& Occupational Health, in a temperature and relative humidity-controlled glove box (PlasLabs Model 890 THC) using an ultra-microbalance (Mettler Toledo Model $\mathrm{XP2U}$ ) for total $\mathrm{PM}_{2.5}$ mass, and reflectometry for $\mathrm{BC}$ absorbance was performed using the EEL43M Smokestain Reflectometer (Diffusion Systems). Ogawa passive badges were analyzed at the University of Pittsburgh, Department of Geology \& Planetary Sciences using water-based extraction and spectrophotometry (Thermo Scientific Evolution $60 \mathrm{~S}$ UV-Visible Spectrophotometer) for $\mathrm{NO}_{2}$ ppb concentration. $\mathrm{SO}_{2}$ and $\mathrm{O}_{3}$ sample analyses are ongoing, and we do not report their results here.

\section{Quality assurance and controls}

To account for possible contamination, we used one laboratory blank and multiple field blanks each session for gases and particles, and co-located paired distributed monitors at four randomly-selected sites during one sampling session each season. $\mathrm{PM}_{2.5}$ pump flow rates were calibrated to 4.0 liters per minute (LPM) (temperatureadjusted based on weather forecasts) prior to deployment, and compared to post-collection rates. We verified program completion for each sampler run using the sampling unit program log.

Summer sampling was performed from July 25 to September 9, 2011 (the week of August 29 skipped for 
logistical reasons), and winter sampling from January 16 to February 24, 2012. Across seasons, all $\mathrm{PM}_{2.5}$ samples met acceptable pre- and post-collection flow rate (within $5 \%$ of $4.0 \mathrm{LPM}$ ). Instrumentation failure occurred at only one site, which was re-sampled during a later session. Colocated measures of $\mathrm{PM}_{2.5}$ and $\mathrm{NO}_{2}$ were highly correlated (rho $=0.93$ and 0.97 , respectively) across four monitoring locations. Field blanks for $\mathrm{PM}_{2.5}$ and $\mathrm{NO}_{2}$ ranged from $0.07-1.50 \mu \mathrm{g} / \mathrm{m}^{3}$ and $0.01-0.05 \mathrm{ppb}$, respectively, and were similar across seasons. Pollutant concentrations were field blank-corrected. Data completeness was 100\% for $\mathrm{PM}_{2.5}, \mathrm{NO}_{2}$, and $\mathrm{BC}$, with no statistical outliers (outside of mean $+/-3$ standard deviations).

\section{Study domain selection and characterization}

We aimed to capture large industrial point sources, major roadways, and river valleys across an urban-tosuburban gradient of Allegheny County, within a feasible coverage area, extending at least $10 \mathrm{~km}$ Northeast of industrial point sources, with respect to the prevailing wind direction (West/Southwest). In a GIS, we fit a polygon to meet coverage and distance criteria, and selected intersecting contiguous census tracts, to enable subsequent merging of population indicators. Our domain stretched northwest of downtown Pittsburgh along the Ohio River, and southeast along the Monongahela River, covering approximately $500 \mathrm{~km}^{2}$, including 258 contiguous census tracts within Allegheny County, PA (Figure 1), and captured wide variability in population density: from 272 to 55,343 residents per $\mathrm{km}^{2}$ [24]. Large industrial point sources within our domain include two coke smelting works (Neville Island and Clairton) and a steel mill (Braddock).

For purposes of sampling site selection, we explored spatial variability across a range of local source indicators, and potential modifiers of source-concentration relationships. Based on recent source apportionment of $\mathrm{PM}_{2.5}$ measurements collected at Allegheny County Health Department (ACHD) regulatory monitors, which attributed the majority of measured fine particles to local industrial and mobile sources [19], we developed GIS-based indicators of local industrial emissions and on-road vehicle traffic. Because traffic-related pollution varies within 50-200 $\mathrm{m}$ from roadways [33,34], and because of steep elevation gradients in the Pittsburgh area, we used relatively small regular $100 \mathrm{~m}^{2}$ lattice grid cells to characterize the study domain according to three key local pollution indicators: (a) traffic density, (b) emissionweighted proximity to industrial point sources, and (c) topography. GIS-based analysis and mapping were implemented in ArcInfo, v10 (ESRI, Redlands, CA).

We evaluated multiple indicators of traffic emissions (e.g., proximity to roadways, heavy track traffic), and

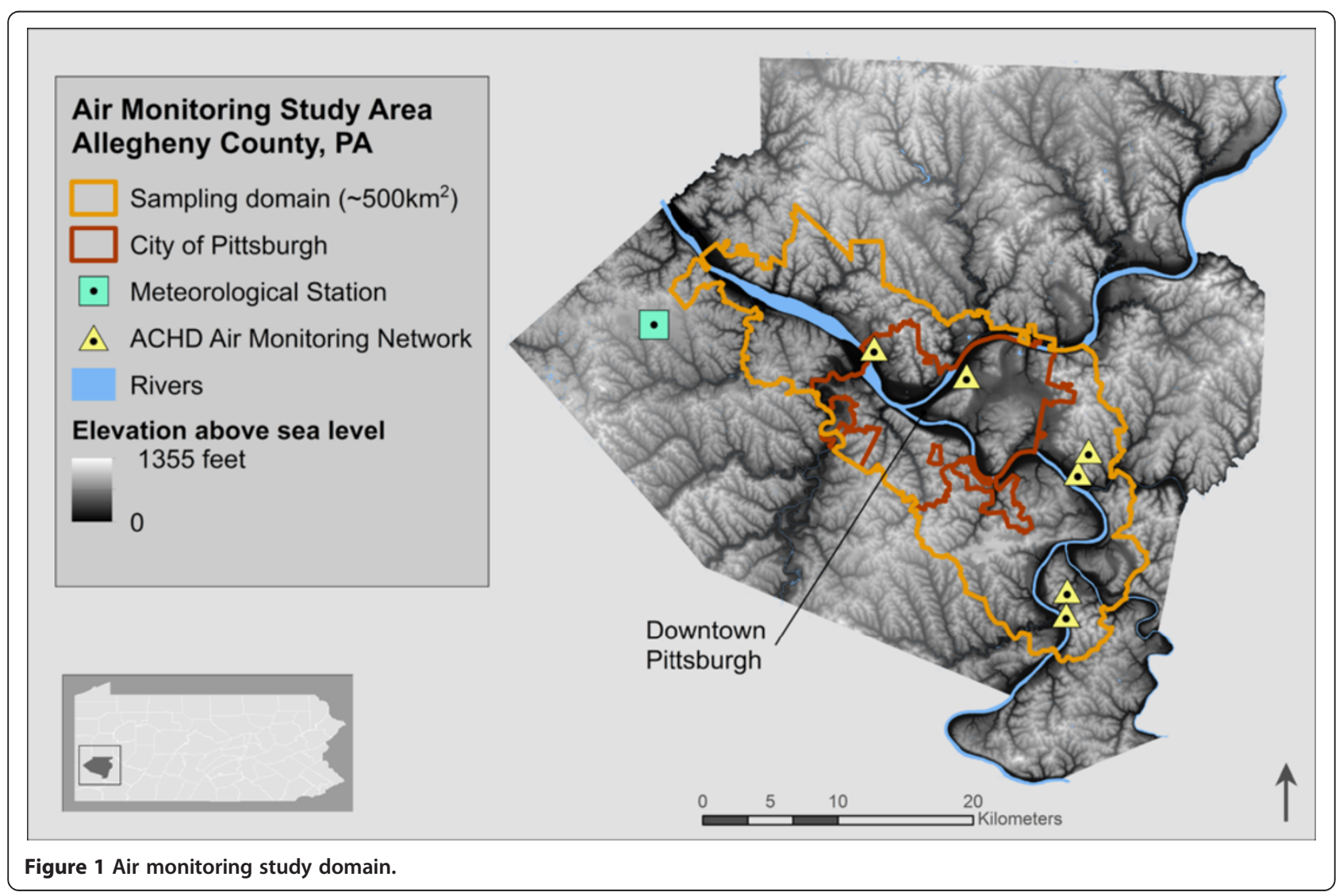


decided on the most inclusive indictor - total on-road traffic density - to prevent biasing our study design toward one class of vehicle emissions. First, we created road-segment counts by summing total vehicles on major road segments plus an estimated 500-vehicle count on minor road segments (based on major road count distribution), using Pennsylvania Department of Transportation Annualized Average Daily Traffic (AADT) counts (2011) [35]. Using ArcInfo's Spatial Analyst toolbox, we derived a continuous kernel traffic density surface by applying a Gaussian decay function to traffic counts on all road segments within our domain. From this traffic density surface, we calculated mean traffic density within each $100 \mathrm{~m}^{2}$ grid cell.

We created a multi-pollutant indicator of industrial emissions to prevent biasing our sampling design toward one pollutant or industry type. Using emissions data from the U.S. Environmental Protection Agency's National Emissions Inventory [36], we first summed emissions mass in tons of multiple pollutants $\mathrm{PM}_{2.5}$ (filterable and condensable), nitrogen oxides $\left(\mathrm{NO}_{\mathrm{X}}\right)$, sulfur dioxide $\left(\mathrm{SO}_{2}\right)$, and volatile organic compounds (VOCs) - from reporting facilities in Allegheny County, PA. We then used inverse-distance interpolation to calculate an emissionweighted proximity to industry indicator for each $100 \mathrm{~m}^{2}$ grid cell centroid, drawing emissions information from facilities within an $80 \mathrm{~km}$ radial buffer threshold. Inverse-distance interpolation weights emissions values at locations in between facilities as a function of distance, such that relatively near facilities will have a greater influence than far facilities on local air quality.

As there is no standard metric to demarcate 'valley' versus 'non-valley' areas, we opted to use continuous elevation above sea level to maximize spatial resolution and comparability with previous LUR studies [8,37-39]. We calculated mean elevation within each $100 \mathrm{~m}^{2}$ grid cell from the U.S. Geological Survey National Elevation Dataset $30 \mathrm{~m}^{2}$-resolution raster data set [40]. Across sampling locations, elevation is correlated with distanceto-river-centerlines at rho $=0.67$, supporting our interpretation of elevation as an indicator of river valleys, where cool air pools may exacerbate inversion formation. Furthermore, in our pilot mobile monitoring study, we found a strong relationship between elevation, atmospheric inversions, and $\mathrm{PM}_{2.5}$ and $\mathrm{PM}_{10}$ concentrations in one relatively low-lying Pittsburgh community (Braddock, PA) [32].

\section{Distributed site selection \& allocation}

Across our study domain, the distribution of source indicators used for sampling site selection - traffic density, emission-weighted proximity to industrial facilities, and elevation - varied substantially (Figure 2); source indicators were not collinear ( $\mathrm{rho}=-0.08$ to -0.21 , across all $100 \mathrm{~m}^{2}$ grid cells). We dichotomized each source indicator at the $70^{\text {th }}$ percentile, and cross-stratified each $100 \mathrm{~m}^{2}$ grid cell across eight classifications, representing combinations of 'high' and 'low' source profiles (e.g., 'low' traffic

\section{Spatial Heterogeneity in Air Quality Indicators \& Monitoring Site Allocation

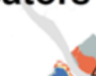

$\Delta$ Study monitoring sites $(\mathrm{n}=36)$
$*$ Urban background site
$*$ Regional background site
Site Selection Strata
Low traffic, Non-valley, Far from industry
Low traffic, Non-valley, Near industry
Low traffic, Valley, Far from industry
Low traffic, Valley, Near industry
High traffic, Non-valley, Far from industry
High traffic, Non-valley, Near industry
High traffic, Valley, Far from industry
High traffic, Valley, Near industry
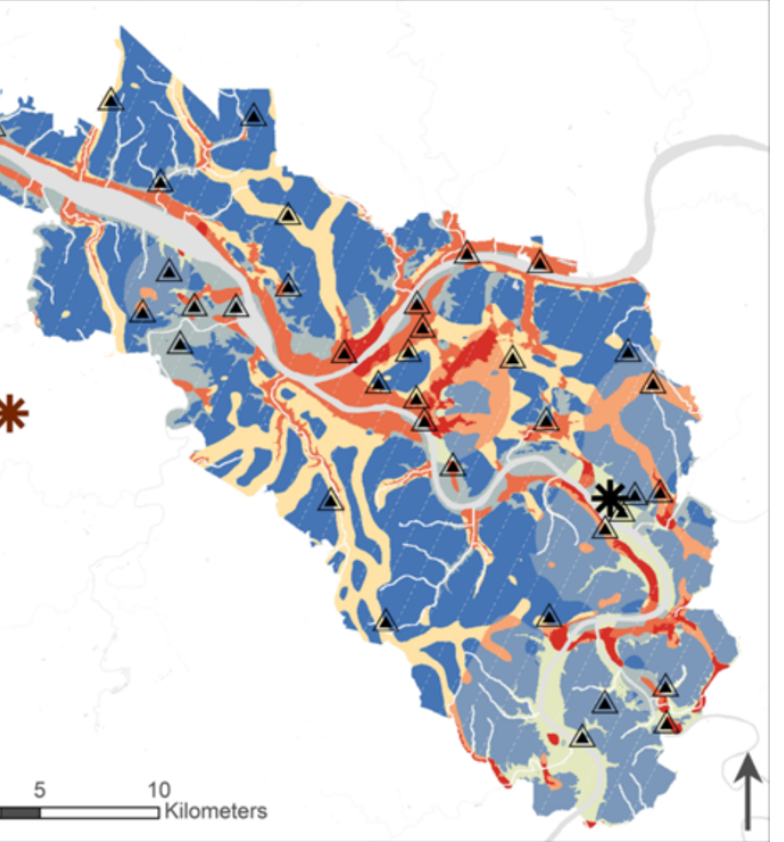

Figure 2 Pollution monitoring locations across source indicators and inversion-prone areas. 
density, 'near' industrial sources, low elevation 'valley'). This dichotomization point was chosen based on leftskewed distribution of source indicators, to systematically over-sample hypothesized high-pollution areas.

We used stratified random sampling without replacement to select 30 spatially-distributed monitoring grid cells across eight source indicator cross-strata, using Geospatial Modeling Environment software, v 0.7.2.0 (Spatial Ecology, LLC). Six additional grid cells were selected to fill spatial gaps in the periphery of our large domain. Specifically, three $30 \mathrm{~km}^{2}$ areas in which no cells had been allocated were selected in GIS, and two cells randomly selected from each. Rivers and riverbank areas $(<20 \mathrm{~m}$ from a river's edge) were not eligible for sampling site selection, for logistical reasons. Sample size was determined by available resources, domain size, logistical limitations, and precedent of 40 monitoring sites for urban LUR modeling [41,42]. Figure 2 shows spatial allocation of distributed and reference monitoring sites, which were repeated in summer and winter.

Suitable locations to mount sampling units (e.g., utility or telephone poles) were identified near the centroid of selected $100 \mathrm{~m}^{2}$ grid cells by field teams, using consistent protocols. Mounting pole eligibility criteria included: no obstructions within $3 \mathrm{~m}$ of the monitors, street accessible, three or more meters from buildings, identifiable pole ownership (to obtain permissions), away from bus stops, and without overhanging tree branches. Latitude and longitude coordinates of selected mounting poles were pinpointed using GPS (Colorado $400 \mathrm{t}$, Garmin), and verified in Google Earth ${ }^{\mathrm{Tw}}$. A detailed site survey was conducted for each sampling location, to document relevant information potentially unavailable in GIS datasets (e.g., construction). Permissions to mount monitors on utility poles were obtained from Duquesne Light Co., Verizon, Inc., Allegheny County Parks Department, and the City of Pittsburgh Department of Public Works.

As sampling at the 36 sites was evenly allocated across six Monday-through-Friday sampling sessions (six sites sampled per session), we sought to balance source indicator strata and spatial distribution across sessions to avoid confounding spatial and temporal patterns in pollution concentrations. For each session, we used traffic density, the most spatially dispersed indicator, to draw a stratified-random sample (without replacement) of six sites (e.g., randomly allocate 3 'high' and 'low' traffic density sites per session). Because pollution source and topography indicators may be spatially clustered in Pittsburgh (i.e., industrial facilities located in lowelevation river valleys and/or near highways), we required spatial representation of four regions of our domain (i.e., east and west banks of the Monongahela River, northeast and southeast of downtown) within each session. Temporal allocation of sites across sessions was the same during winter and summer sampling seasons.

\section{Reference monitors and temporal adjustment}

We designated two reference sites, which were sampled during all sessions to provide information on overall temporal trends in air quality. First, an upwind reference site (Regional background site - Figure 2) located in a relatively rural area west of our domain, in Settlers Cabin County Park, Oakdale, PA, would provide information on regional background air quality. Second, a relatively urban reference site (Urban background site Figure 2) within our domain, in Braddock, PA, was selected for comparison. The urban reference site is located in a low-elevation area, to capture topography-related inversion effects in seasonal air quality trends. We compared ACHD regulatory monitoring data to the weekly temporal patterns in $\mathrm{NO}_{2}$ and $\mathrm{PM}_{2.5}$ measured at study reference monitors, and found variable correlation between both reference monitors with ACHD monitors (Spearman rho from -0.71 to $0.90($ mean $=0.23)$ ). Figure 3 plots weekly $\mathrm{PM}_{2.5}$ and $\mathrm{NO}_{2}$, trends across ACHD regulatory monitors and study reference monitors (regional and urban background); regional and urban reference trends are variably correlated in both seasons (Spearman rho 0.04 to 0.91 ). As expected, regional background concentrations were consistently lower than urban reference site measurements, and lower than ACHD regulatory monitors. This difference is larger for $\mathrm{NO}_{2}$ in both seasons, compared to $\mathrm{PM}_{2.5}$.

To facilitate comparison between site-specific concentrations, collected during one of six sampling sessions, we apply a temporal adjustment to adjust distributed site samples for between-session variability primarily driven by time-varying meteorology or long-range transport, and to derive seasonally representative mean values. Specifically, to estimate the expected, seasonally representative concentration at a given site - as if it had been sampled during an "average" week - the observed concentration is multiplied by the ratio of the seasonal average reference concentration, and then divided by the session-specific reference concentration. As such, it is the relationship of the session relative to the seasonal average at the reference site(s) that determines the temporal adjustment, which can therefore adjust distributed concentration to both lesser and greater values. These adjusted seasonal mean values allow for examination of spatial source-concentration relationships, with reduced influence of time-varying factors (i.e., meteorology, longrange transport). Because the appropriate reference trend for temporal adjustment may vary by season and/or pollutant, we evaluate two methods: one using the only the regional background reference trend (Equation 1), and a second using the mean trend of the urban and regional 

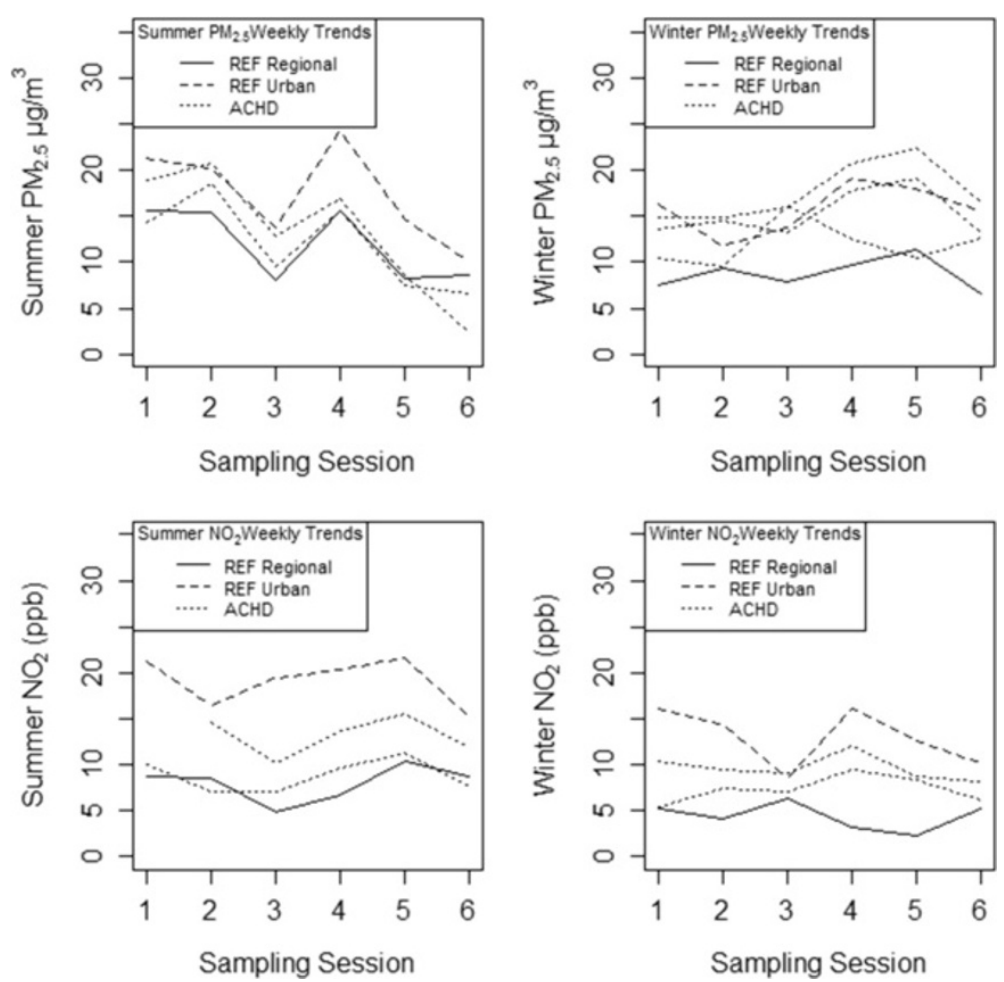

Figure 3 Weekly $\mathrm{PM}_{2.5}$ and $\mathrm{NO}_{2}$ trends between study reference sites and ACHD regulatory monitors, by season.

background sites (Equation 2). Both of these approaches have been successfully applied in other studies of intraurban air quality variability $[7,16]$.

Within each season, sampled pollutant concentrations were temporally adjusted as:

$$
[\operatorname{adjConc}]_{\mathrm{ij}}=\frac{[\text { Conc }]_{\mathrm{ij}}}{\left[\operatorname{Ref}_{\text {Regional }}\right]_{\mathrm{j}}} *\left[\operatorname{Ref}_{\text {Regional }}\right]_{\text {Season }}
$$

$$
[\text { adjConc }]_{\mathrm{ij}}=\frac{[\text { Conc }]_{\mathrm{ij}}}{\left[\operatorname{Ref}_{\mu(\text { Regional }+ \text { Urban })}\right]_{\mathrm{j}}} *\left[\operatorname{Ref}_{\mu(\text { Regional }+\mathrm{Urban})}\right]_{\text {Season }}
$$

where $[\operatorname{adjConc}]_{\mathrm{ij}}$ is the temporally-adjusted pollutant concentration at monitoring site i during sampling session $\mathrm{j},[\mathrm{Conc}]_{\mathrm{ij}}$ is the pollutant concentration at monitoring site $i$ during sampling session $j,\left[\operatorname{Ref}_{\text {Regional }}\right]_{j}$ is the regional background reference site concentration during sampling session $\mathrm{j},\left[\operatorname{Ref}_{\mu(\text { Regional+Urban })}\right]_{j}$ is the mean concentration of the regional background and urban reference sites during sampling session $j,\left[\operatorname{Ref}_{\text {Regional }}\right]_{\text {Season }}$ is the seasonal average regional background reference site pollutant concentration, and $\left[\operatorname{Ref}_{\mu(\text { Regional+Urban })}\right]_{\text {Season }}$ is the mean seasonal average pollutant concentration of the regional background and urban reference sites.

\section{Temperature inversions and meteorology}

We identified probable morning inversion hours as 6:0011:00 AM by examining: (a) meteorological sounding data, (b) hourly ACHD regulatory monitor data, and (c) pilot mobile monitoring study data [32]. We used meteorological sounding data (i.e., Skew-T diagrams) recorded daily at 7:00 AM from the Pittsburgh International Airport, approximately $25 \mathrm{~km}$ Northwest of downtown Pittsburgh (Figure 1), to identify lapses in the vertical temperature gradient characteristic of inversion events. To confirm the number of inversion hours overlapping with sampling intervals (6:00-11:00 AM), inversion hours per event were evaluated using Bufkit 10.11, a forecast profile visualization and analysis software developed by the National Oceanic and Atmospheric Association (NOAA) and National Weather Service [32]. Inversions were defined as two or more hours of inverted temperature gradient during sampling hours. Inversion frequency was operationalized as number of inversion mornings per sampling session (1-4), and as a binary indicator (fewer than 3, vs. 3 or more days per session), based on overall frequency distribution. Importantly, these characterizations are regional scale, and do not reflect the complex interactions between topography, surface thermal variability in urbanized areas (i.e., urban heat island effect), and pollution. 
Wind speed and direction influence local pollution concentrations through horizontal advection, however, the metrics that can elucidate spatial gradients in these processes are not well specified [43]. Wind speed and direction data measured at NOAA's weather station at the Pittsburgh International Airport (and obtained from NOAA's online National Climatic Data Center) were clipped to each sampling session, and used to generate wind rose diagrams (using Lakes Environmental WRPLOT View freeware) to examine within and between session variability. We then determined dominant wind direction and average wind speed (from any direction) for each sampling session. We compared wind speed and direction on inversion versus non-inversion mornings, in each season, to better understand the relationship between inversion conditions and local pollutant concentrations.

\section{Statistical analysis}

We calculated descriptive statistics for $\mathrm{PM}_{2.5}, \mathrm{BC}$ and $\mathrm{NO}_{2}$, during each season, to identify potential outliers, and to compare temporally adjusted values by method (i.e., Regional-only vs. Urban + Regional). We examined pollutant concentration distributions across pollution indicator strata used for site selection and allocation: traffic density, emission-weighted proximity to industry, and elevation above sea level using Spearman correlation analysis, to account for non-normal distribution of pollution concentrations. We examined between-season differences using paired t-tests on log-transformed (base 10) concentrations, to account for non-normality of distributions, and compared results across temporal adjustment methods. We examined the relationship between logtransformed pollutant concentrations and inversion frequency, by elevation and temporal adjustment method. Further analyses of meteorological factors examined associations between temporally adjusted pollutant concentrations and within-session average wind speed (continuous and binary (median-stratified) measures), and dominant wind direction (e.g., West, Northwest). Statistical analyses were performed in SAS, v 9.2 (Cary, NC) and R statistical software v 2.12.1.

\section{Results}

$\mathrm{PM}_{2.5}, \mathrm{BC}$, and $\mathrm{NO}_{2}$ concentrations varied across monitoring locations, capturing a wider range of concentrations than at ACHD regulatory monitoring locations during corresponding sampling weeks. Table 1 reports summary statistics of pollutant concentrations measured across distributed sites, by season, and compares temporal adjustment methods (Equations 1 and 2). Under both temporal adjustment methods, $\mathrm{NO}_{2}$ concentrations were higher during winter $(\mathrm{p}<0.001)$, and $\mathrm{PM}_{2.5}$ concentrations were higher during summer sampling $(\mathrm{p}<0.10)$. Within-season, distributed pollution measurements varied by temporal adjustment method, (e.g., summer $\mathrm{NO}_{2}$ under regional-only vs. urban and regional background adjustment), with Spearman rho values ranging from 0.59 to 0.95 . Specifically, adjustment using the mean of urban and regional background trends (Equation 2) produced attenuated seasonal average concentrations across sites, particularly for $\mathrm{NO}_{2}$, in both seasons (Table 1). Weakest between-method correlations were observed for summer $\mathrm{NO}_{2}$ and winter $\mathrm{PM}_{2.5}$ (rho 0.59 and 0.60 , respectively), and strongest correlation for $\mathrm{BC}$ in both seasons (summer rho 0.81, winter 0.95).

Figures 4 and 5 show scatterplots comparing relationships between sampled pollutant concentrations and pollution indicators, by season, under temporal adjustment Equation 2. In both seasons, measured concentrations were inversely correlated with elevation (i.e., river valley); stronger correlations occurred during winter sampling (Spearman rho -0.42 to -0.72 ), and $\mathrm{PM}_{2.5}$ showed the weakest correlation with elevation, overall (summer rho -0.11, winter -0.42). Traffic density was positively correlated with $\mathrm{NO}_{2}$ concentrations, in both seasons (summer rho 0.33, winter 0.36). Emission-weighted proximity to industry, a highly left-skewed indicator, was not significantly correlated (i.e., $\mathrm{p}<0.05$ ) with measured pollution concentrations in either season. Under regional background temporal adjustment (Equation 1), correlation patterns are qualitatively similar, with notable exceptions: a) the inverse relationship between elevation and pollutant concentrations is attenuated by at least $10 \%$

Table 1 Summary statistics of $\mathrm{PM}_{2.5}\left(\mu \mathrm{g} / \mathrm{m}^{3}\right), \mathrm{BC}(\mathrm{abs})$, and $\mathrm{NO}_{2}$ (ppb) concentrations, by season, comparing temporal adjustment methods

\begin{tabular}{|c|c|c|c|c|c|c|c|c|}
\hline & \multicolumn{4}{|c|}{ Urban and Background Adjustment $(n=36)$} & \multicolumn{4}{|c|}{ Background-only Temporal Adjustment ( $n=36)$} \\
\hline & Mean & SD & Minimum & Maximum & Mean & SD & Minimum & Maximum \\
\hline Summer $\mathrm{PM}_{2.5}\left(\mu \mathrm{g} / \mathrm{m}^{3}\right)$ & 14.00 & 3.68 & 1.28 & 21.06 & 14.24 & 3.97 & 1.33 & 22.71 \\
\hline Summer BC (abs) & 1.58 & 0.85 & 0.02 & 4.82 & 1.61 & 0.91 & 0.02 & 4.64 \\
\hline Summer $\mathrm{NO}_{2}$ (ppb) & 10.75 & 3.36 & 5.12 & 17.25 & 12.30 & 6.50 & 4.46 & 27.72 \\
\hline Winter $\mathrm{PM}_{2.5}\left(\mu \mathrm{g} / \mathrm{m}^{3}\right)$ & 12.53 & 2.28 & 8.28 & 16.98 & 12.64 & 2.52 & 8.02 & 20.10 \\
\hline Winter BC (abs) & 1.31 & 0.55 & 0.63 & 2.99 & 1.31 & 0.53 & 0.70 & 2.72 \\
\hline Winter $\mathrm{NO}_{2}(\mathrm{ppb})$ & 17.93 & 3.90 & 9.93 & 25.60 & 18.69 & 6.21 & 10.90 & 34.10 \\
\hline
\end{tabular}




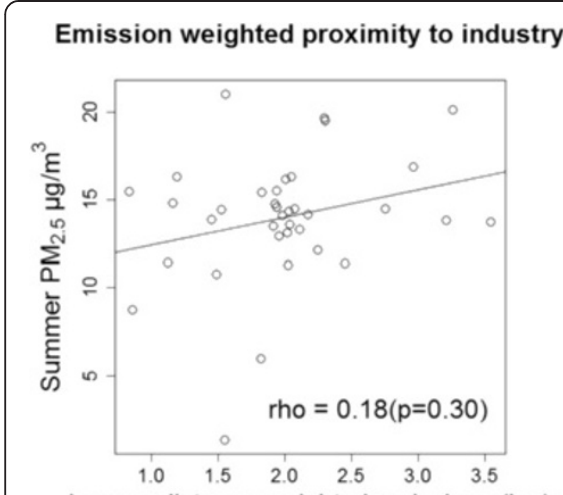

Inverse distance-weighted emissions (log)
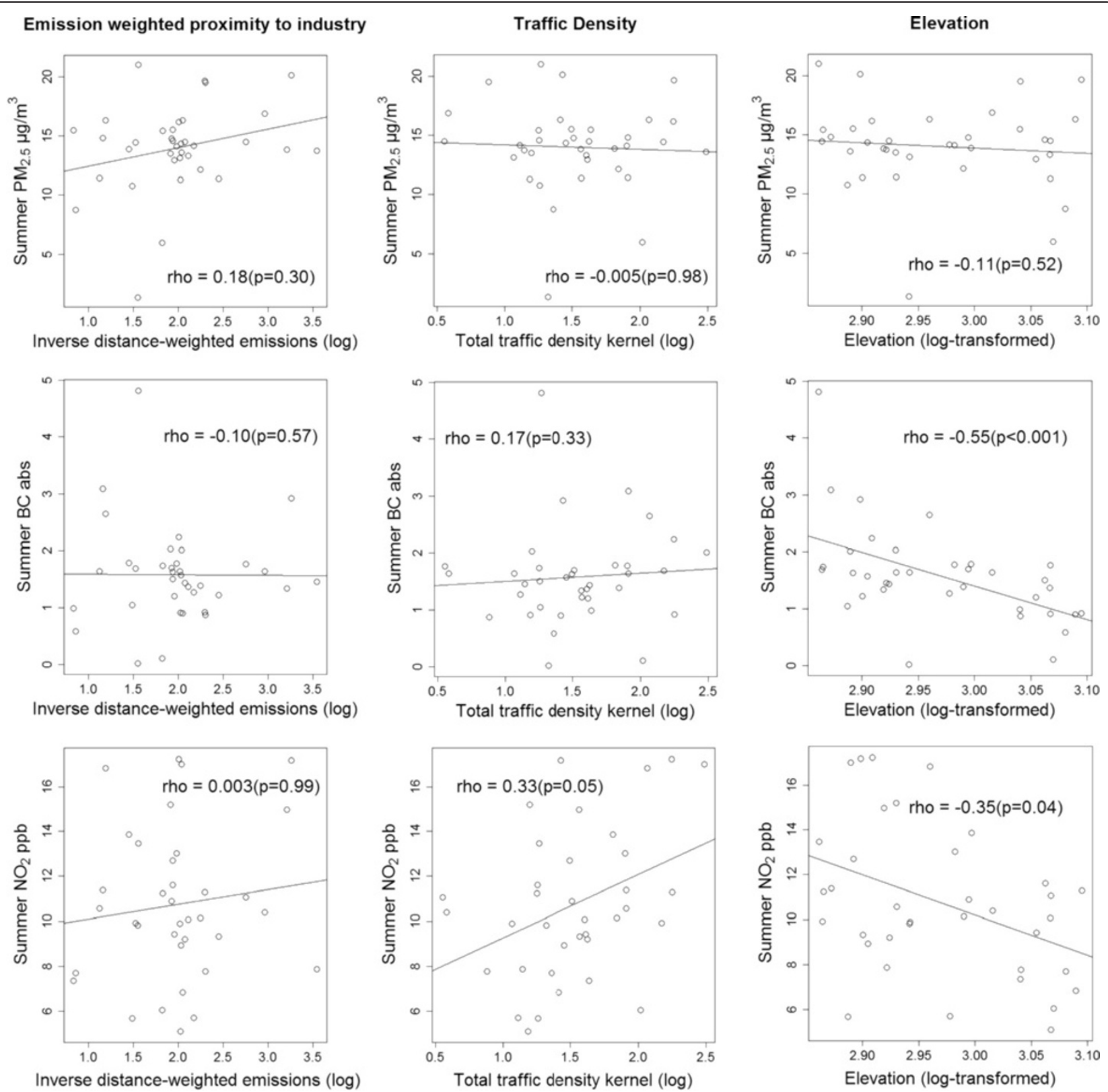

Figure 4 Summer $\mathrm{PM}_{2.5}, \mathrm{BC}$ and $\mathrm{NO}_{2}$ concentrations across source indicators and elevation (temporally adjusted using regional and urban background reference trends).

across pollutants and seasons; b) traffic density is not significantly correlated ( $\mathrm{p}>0.05$ ) with $\mathrm{NO}_{2}$ in either season (summer rho 0.01, winter 0.19); and c) summer $\mathrm{PM}_{2.5}$ is more strongly correlated with emission-weighted proximity to industry (rho 0.32, $\mathrm{p}=0.05$ ) (Additional file 1: Figures S1 and Additional file 2: Figure S2).

Temperature inversion conditions were slightly more common during winter ( 2 to 4 mornings per 5 -day sampling session) than summer sampling (1 to 3 mornings per session). Wind rose diagrams comparing inversion vs. non-inversion mornings show differing patterns in wind speed and direction (Figure 6). Across summer inversion mornings, wind directions were variable, with roughly $50 \%$ of all winds coming from either West, Northwest or South-Southeast directions, compared to predominantly Westerly winds on non-inversion mornings. Winds on winter inversion mornings were predominantly from the West and West-Southwest directions, while non-inversion morning winds were predominantly from the Southwest. Overall, wind speeds were generally higher during winter sampling sessions (winter mean = $3.20 \mathrm{~m} / \mathrm{sec}$, vs. summer mean $=1.79 \mathrm{~m} / \mathrm{sec}$ ), and sessions 

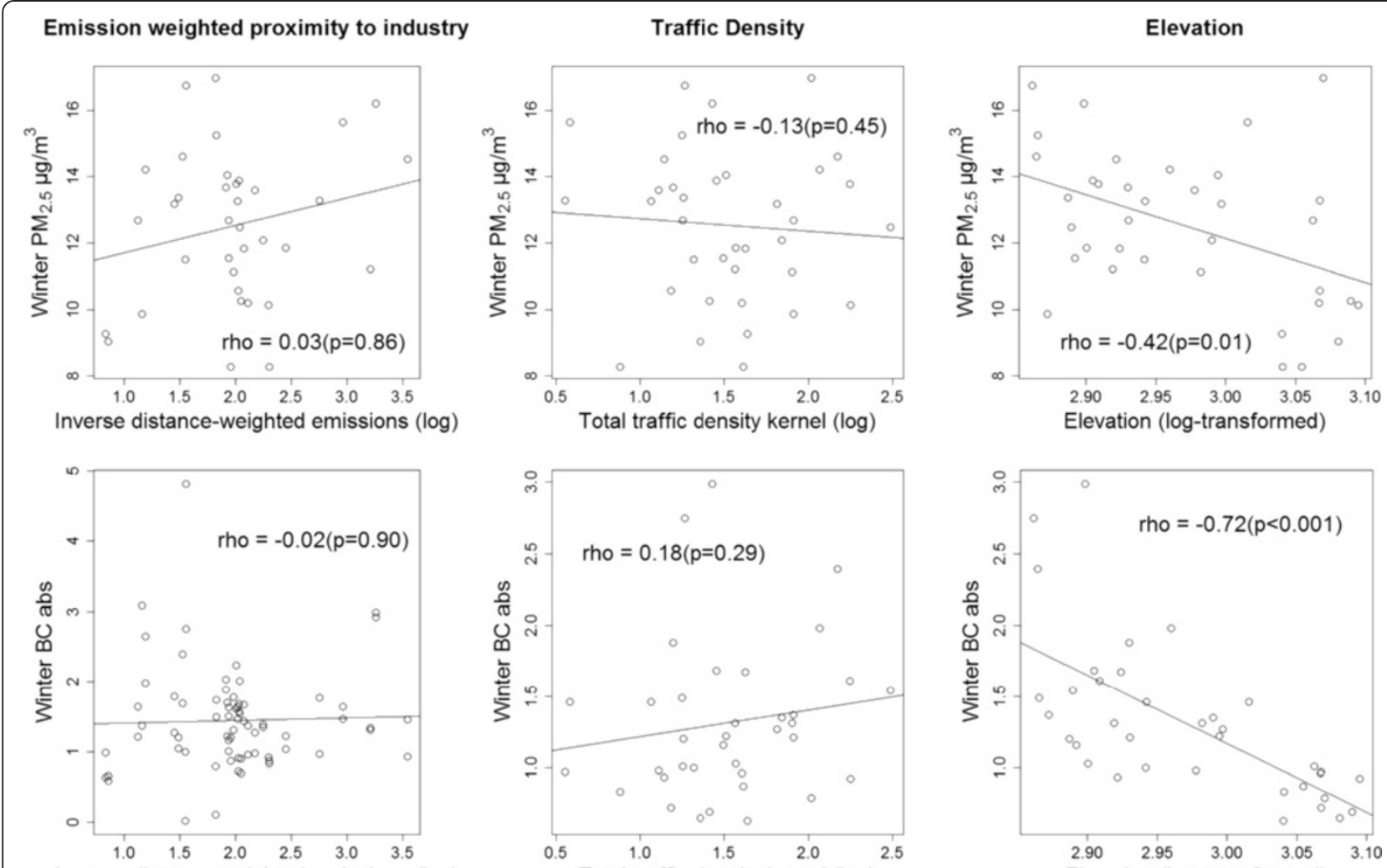

Inverse distance-weighted emissions (log)
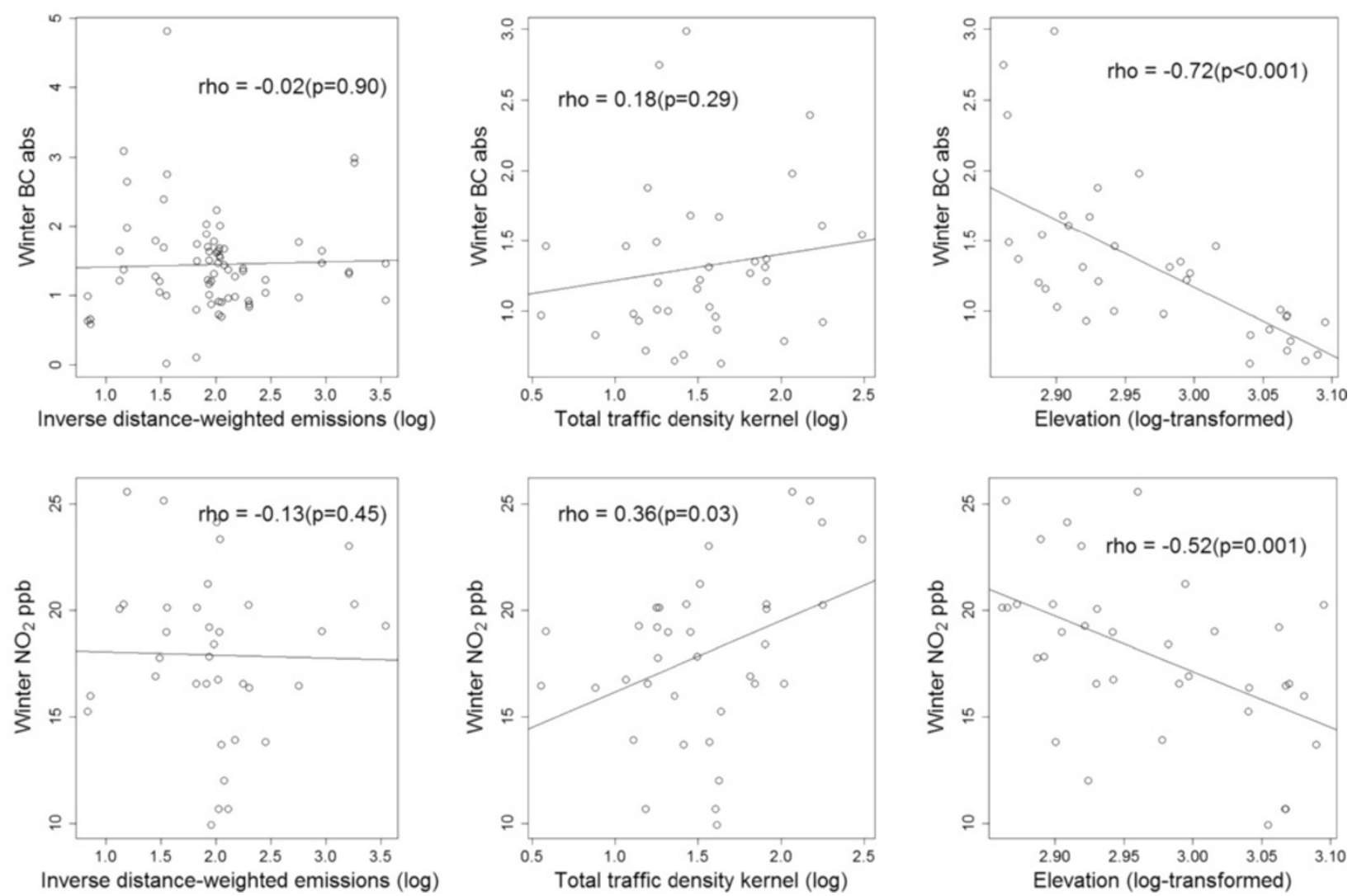

Figure $\mathbf{5}$ Winter pollutant concentrations across source indicators and elevation (temporally adjusted using regional and urban background reference trends).

with lower average wind speeds (stratified at median) had higher concentrations of summer $\mathrm{NO}_{2}$ and winter $\mathrm{BC}(\mathrm{p}<0.05)$. Dominant wind directions were associated with winter $\mathrm{PM}_{2.5}$ (winds form South/Southwest) and winter $\mathrm{NO}_{2}$ (West/Northwest) concentrations, but not summer.

Figure 7 compares the relationship between inversion frequency and pollutant concentrations, by temporal adjustment method, illustrating the importance of adjustment method for assessing the role of short-term meteorological events in spatial saturation studies. $\mathrm{NO}_{2}$ concentrations increased with number of inversion mornings per 5-day sampling session under the temporal adjustment method drawing information from both regional and local temporal trends (Equation 2), but not under regional-only adjustment (Equation 1). These relationships did not vary by season. This positive relationship between inversion frequency and $\mathrm{NO}_{2}$ was present among low- and high-elevation sites, however, with higher concentrations across low-elevation sights (Figure 8). 


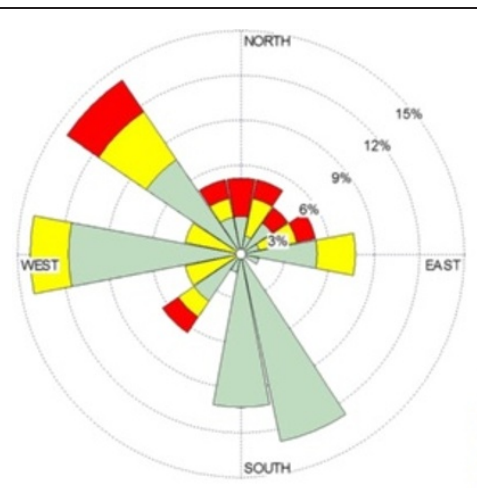

Summer Sampling Inversion Mornings $(n=13)$

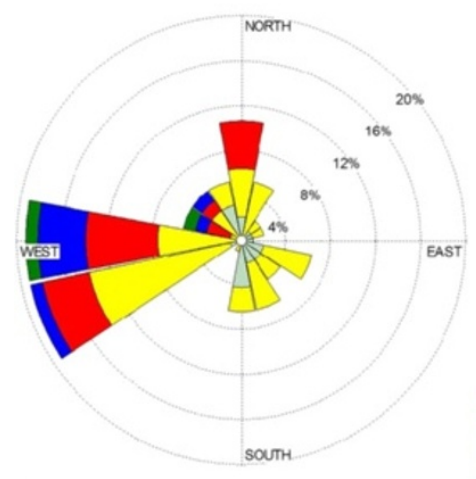

Winter Sampling Inversion Mornings ( $n=19)$
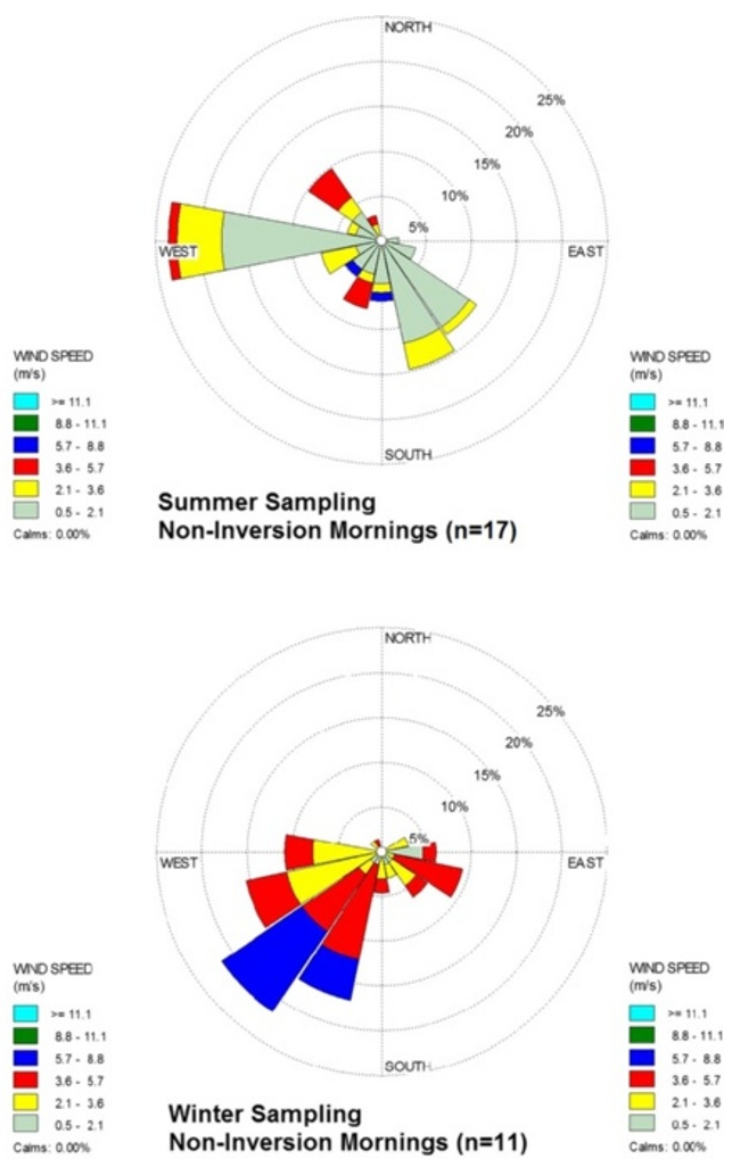

Figure 6 Wind direction and speed on inversion vs. non-inversion sampling mornings, by season.

\section{Discussion}

We present an approach for capturing intra-urban spatial contrasts in pollution concentrations, across complex terrain, during select hours of the day - here, to examine meteorological regimes. Our spatial saturation design captured source heterogeneity across our study domain, minimized spatial and temporal confounding within and across sampling sessions, and included topographic indicators to provide additional information on intraurban variability in air quality. We offer an approach towards better understanding the impacts of short-term temperature inversions on spatial variation in air quality, by leveraging a programmable spatial monitoring system, diurnal variation in meteorology, and spatial gradients in topographic modifiers (i.e., elevation), and compare the efficacy of multiple temporal adjustment methods for this temporally-stratified spatial dataset.

This is the first study, to our knowledge, to use a spatial saturation approach to disentangle local pollution sources across the Pittsburgh region, with specific attention to complex terrain and atmospheric inversions. We observed seasonal differences in pollutant concentrations, and spatially-distributed sampling captured greater variability in pollutant concentrations than did County regulatory monitors. $\mathrm{PM}_{2.5}$ concentrations were higher during summer sampling, consistent with a previous central-site particle monitoring study in Pittsburgh [22], and $\mathrm{NO}_{2}$ concentrations were higher during winter sampling.

We examined two temporal adjustment methods for deriving seasonal mean concentration estimates at distributed locations, and found that the choice of reference site(s) influenced observed relationships between measured concentrations and emissions indicator strata (i.e., elevation, traffic density, industrial emissions) for $\mathrm{NO}_{2}$, but not for $\mathrm{PM}_{2.5}$ or BC. This discrepancy is likely because our upwind (regional) site, in a sparely-populated area, effectively captured background variation in nonreactive pollutants with upwind sources (such as $\mathrm{PM}_{2.5}$ or $\mathrm{BC}$ ), but not highly photochemically reactive pollutants (such as $\mathrm{NO}_{2}$ ). Averaging the two reference monitors effectively captured some aspects of both the regional (i.e., long-range transport, meteorology) and local (i.e., topography, urban source activity variation) time-varying factors that influence intra-urban air quality. As such, we found that the appropriate background reference trend 

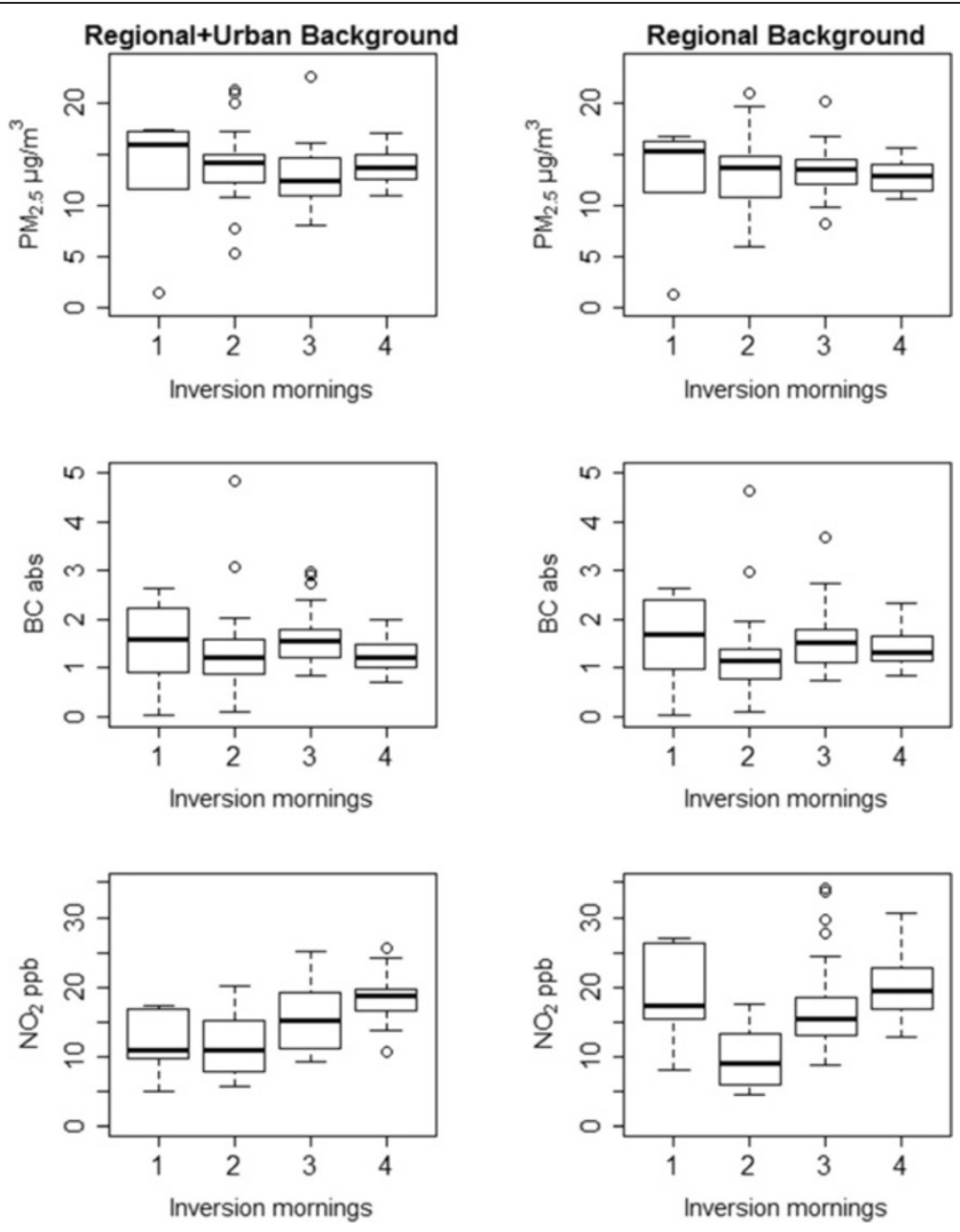

Figure 7 Pollutant concentrations by inversion frequency, by temporal adjustment method.

differs between pollutants, and determined that temporal adjustment using regional and urban background trends was more robust for a multi-pollutant study with a focus on potential meteorological effects on local concentrations.

While the pollution source indicators used to allocate sampling sites were consistent with the LUR literature, we did not find strong overall relationships between measured pollutants and traffic density or emissionsweighted proximity to industry. This is not entirely surprising, as the GIS-based indicators used for site selection and allocation were intentionally inclusive of multiple components of source activity. For example, we developed a multi-pollutant indicator of industrial emissions to prevent biasing study design toward one type of facility or chemical, and this underlying study design is well-suited for future LUR models that will use refined metrics (e.g., $\mathrm{SO}_{2}$ emissions in tons, stack height). Likewise, our traffic density indicator includes total vehicle counts on major and minor roads, but local trafficrelated pollution may be driven by specific aspects of traffic patterns (e.g., average vehicle speed, idling) and fleet composition (e.g., diesel trucks, bus traffic).

An alternate explanation for weak overall sourceconcentration relationships are modifying effects of topography and meteorology. Across our distributed monitoring sites, elevation was inversely associated with $\mathrm{BC}$ and $\mathrm{NO}_{2}$ concentrations, in both seasons. Among low-elevation sites, where we hypothesized that inversion effects would be exacerbated, $\mathrm{NO}_{2}$ concentrations were higher during sampling sessions with 3 or more inversion mornings across low-elevation monitoring sites, but no statistically significant differences were found for $\mathrm{PM}_{2.5}$ or $\mathrm{BC}$. This finding suggests that inversions have different effects across pollutants. This difference may by a function of local sources versus long-range pollution transport; if $\mathrm{PM}_{2.5}$ predominantly originates from long-range sources, it may demonstrate lesser local trapping in industrial valleys during inversion events, while the opposite may be true for $\mathrm{BC}$ and $\mathrm{NO}_{2}$, if they primarily arise from local sources. Lower regional wind speeds on inversion 

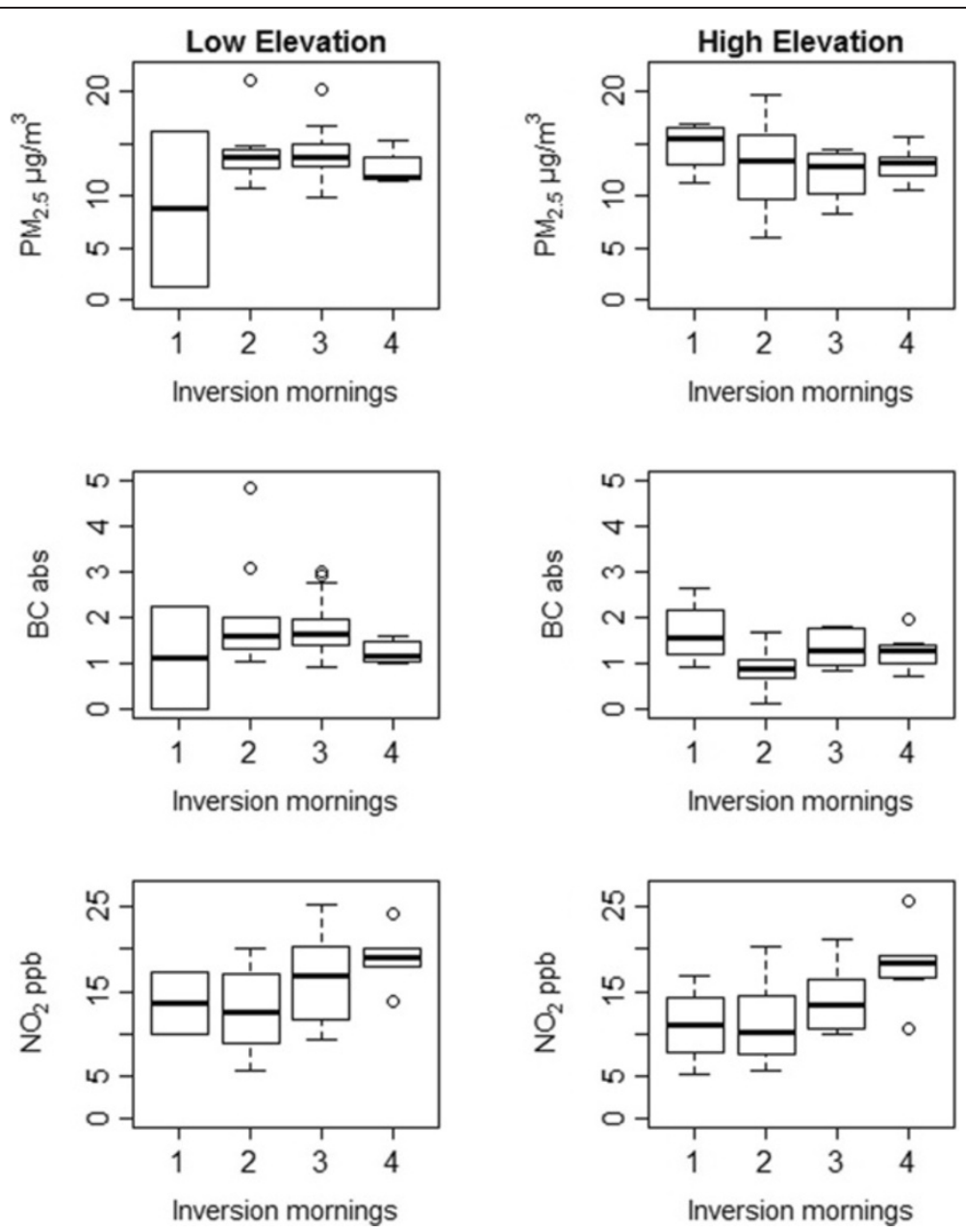

Figure 8 Pollutant concentrations by inversion frequency, among low- and high-elevation monitoring sites ( $\mathrm{n}=36$ in each group).

mornings also help explain different effects across pollutants, particularly during summer sampling; higher $\mathrm{NO}_{2}$ and $\mathrm{BC}$ during sampling sessions with multiple inversions may be attributable to less advection and dispersion of locally-generated pollutants, compared to long-range $\mathrm{PM}_{2.5}$. Other potential explanations for different observed inversion effects across pollutants, which are not mutually exclusive, include vertical emission location (i.e., industrial stacks versus on-road traffic), and atmospheric chemistry (i.e., reactivity and transformation rates) [44].

These findings are in keeping with other urban-scale (as opposed to simulation or regional-scale) monitoring studies of inversion effects on pollutants. Wallace et al. (2010) identified similar differential inversion effects by elevation in a mobile monitoring study in Hamilton, Ontario, but saw effects for both $\mathrm{PM}_{2.5}$ and $\mathrm{NO}_{2}$ [45]. These inconsistent $\mathrm{PM}_{2.5}$ findings may be due to different topography-meteorology interactions in Hamilton (steep escarpment dividing the city into contiguous elevation zones), versus Pittsburgh (complex river valleys), or to different study designs; Wallace et al. took multiple observations at six Hamilton locations over three years under variable inversion conditions, while our study collected samples across 36 sites spatially distributed across a finer gradient of source-elevation profiles. In a separate fixed-site $(n=3)$ study of inversion effects on pollutants in Hamilton, Ontario, Wallace and Kanaroglou (2009) identified differential inversion effects on $\mathrm{PM}_{2.5}$ and $\mathrm{NO}_{2}$ by timing of inversion and season, and explained this difference by a range of meteorological factors, including prevailing wind directions [46].

We found some evidence that the impact of inversion conditions on the source-concentration relationship may vary by topography, pointing to complex challenges for integrating meteorological factors into saturation studies. Spatially, regional-scale meteorological data (e.g., atmospheric sounding, airport-measured wind direction) may not accurately capture intra-urban spatial variation of inversion dynamics. For example, the thermal profile of urban areas differs from relatively suburban areas, and katabatic cold air drainage from more densely built, 
warmer areas (i.e., urban heat island) can result in greater heating of clouds and inversion layer thickness, as compared to suburban areas $[47,48]$. Similarly, cool air pooling in river valleys may delay surface warming, and extend inversion conditions longer than reflected by sounding data. Temporally, integrated samples, though well-suited for deriving spatially-refined seasonal concentration estimated, are not ideal for interpreting effects of short-term meteorological events. Our approach examining inversion frequency within integrated sampling sessions was sensitive enough to detect some differences between inversion and non-inversion days, but not to examine how specific inversion characteristics (e.g., mixing height, vertical lapse rate) are implicated in inversion-related pollution effects. However, just as spatial saturation studies control for time-varying dayof-week and within-day variations in pollution source activity (e.g., rush hour) by design, this work, and others' [45], supports conditioning site allocation on topographic modifiers of inversion effects (i.e., elevation) as a useful approach.

\section{Strengths}

A unique strength of our study is the use of programmable monitors to synchronize active $\mathrm{PM}_{2.5}$ sampling across many locations, with a focus on inversion-prone morning rush hours. The primary strength and novelty of this work is the contribution to methods and metrics for understanding the role of topographic and meteorological factors on intra-urban air quality variability using a spatial saturation approach. Strengths of our study design include: monitoring across multiple seasons, measuring multiple pollutants, and spatially saturating a complex domain to systematically disentangle important local exposure factors. Key strengths of our instrumentation and data quality include: sampling near breathing zone height and excellent data quality and completeness. Our site allocation methodology minimized confounding of spatial and temporal factors, and provided useful information for refining and interpreting GIS-based pollution source indicators for LUR modeling.

\section{Limitations}

Regional meteorological measures (e.g., wind speed and direction) limit our ability to assess differential effects on source-concentration relationships; integrated wind measurement instrumentation with each monitor, for example, would be ideal, but infeasible within allowed resources. Temporally, the potential effect of morning inversions on particle concentrations may have been diluted, if highest inversion-related pollution concentrations are found pre-sunrise, as our monitoring began at 6:00 AM, coinciding with morning rush hour. Additionally, low between-session variability in inversion frequency - all sessions in summer and winter had at least one inversion morning - limited examination of pollution effects; this observation also reinforced the importance of understanding this potentially important driver of regional air quality variability. Power calculations for spatial saturation designs vary by location, and 36 sampling locations may have been insufficient to saturate our domain, despite systematic allocation. Though previous LUR studies have cited 40 cites as a minimum for urban monitoring [41,42], and others have successfully used as few as 20 sites [49], one study in New York City demonstrated the utility of as many as 150 sites in a dense, spatially heterogeneous urban area [5,7]. To increase saturation for multi-year LUR modeling, we repeated this study design during a second year (summer and winter). Finally, due to monitoring solely during winter and summer months, we are unable to draw any conclusions about potential interaction of meteorology, topography and pollution during spring and fall seasons.

\section{Conclusion}

In conclusion, we measured wide variability in multiple pollutants across the Pittsburgh metropolitan area, and found some evidence for modification of the inversionconcentration relationship by topography. This work contributes to methods for accurately capturing timevarying factors in spatial saturation studies by design, through targeting specific hours during which meteorological processes are hypothesized to have greatest impacts on local pollution concentrations, utilizing multiple reference monitors to understand spatial heterogeneity in temporal trends, and incorporating topographic gradients, which may interact with meteorological process, in sample allocation.

\section{Additional files}

Additional file 1: Figure S1. Summer $\mathrm{PM}_{2.5}, \mathrm{BC}$ and $\mathrm{NO}_{2}$

concentrations across source indicators and elevation (temporally adjusted using regional reference trend (Equation 1)).

Additional file 2: Figure S2. Winter $\mathrm{PM}_{2.5}, \mathrm{BC}$ and $\mathrm{NO}_{2}$ concentrations across source indicators and elevation (temporally adjusted using regional reference trend (Equation 1)).

\section{Abbreviations}

ACHD: Allegheny County Health Department; AADT: Annualized Average Daily Traffic; BC: Black carbon; GIS: Geographic Information Systems; LPM: liters per minute; LUR: Land use regression; NEl: National Emissions Inventory; $\mathrm{NO}_{2}$ : Nitrogen dioxide; $\mathrm{NO}_{x}$ : Nitrogen oxides; $\mathrm{O}_{3}$ : Ozone; PA: Pennsylvania; $\mathrm{PM}_{2.5}$ : particulate matter; $\mathrm{SO}_{2}$ : Sulfur dioxide; VOC: Volatile organic compound.

\section{Competing interests}

The authors declare that they have no competing interests.

\section{Authors' contributions}

JLCS and DM were primarily responsible for GIS-based analyses and study design. LC, LGC, SG, JH, DM, CR, ST, and BT carried out field implementation and aspects of study design. LC and BT carried out laboratory analyses. BT 
and KNS analyzed meteorological data. JLCS performed statistical analyses. JG and HE supported instrumentation. FH contributed to overall study design, and JEC oversaw all aspects of study design and implementation. All authors read and approved the final manuscript.

\section{Acknowledgements}

The authors are grateful to Dan Bain, of the University of Pittsburgh, Department of Geology \& Planetary Sciences, for assistance with laboratory analysis of gaseous samples. The authors thank the Pittsburgh Department of Public Works (Alan Asbury and Mike Salem), the Parks Department of Allegheny County, and Duquesne Light Co. for monitoring permissions, and the Allegheny County Health Department for regulatory monitoring data support. This work was supported by internal University of Pittsburgh Department of Environmental \& Occupational Health funds.

\section{Author details}

${ }^{1}$ Department of Environmental and Occupational Health, University of Pittsburgh Graduate School of Public Health, Pittsburgh, PA, USA. ${ }^{2} E$ \& G Environmental Diagnostics, LLC, Warwick, NY, USA. ${ }^{3}$ Department of Medicine, Division of Pulmonary, Allergy, and Critical Care Medicine, University of Pittsburgh, Pittsburgh, PA, USA

\section{Received: 12 August 2013 Accepted: 7 April 2014}

Published: 16 April 2014

\section{References}

1. Jerrett M, Burnett RT, Ma R, Pope CA III, Krewski D, Newbold KB, Thurston G, Shi Y, Finkelstein N, Calle EE, Thun MJ: Spatial analysis of Air pollution and mortality in Los Angeles. Epidemiology 2005, 16:727-736.

2. Jerrett M, Arain MA, Kanaroglou P, Beckerman B, Crouse D, Gilbert NL, Brooke JR, Finkelstein N, Finkelstein NM: Modeling the intraurban variability of ambient traffic pollution in Toronto, Canada. J Toxicol Environ Health A 2007, 70:200-212.

3. Ross Z, Jerrett $M$, Ito $K$, Tempalski B, Thurston GD: A land use regression for predicting fine particulate matter concentrations in the New York City region. Atmosph Environ 2007, 41:2255-2269.

4. Clougherty JE, Wright RJ, Baxter LK, Levy Jl: Land use regression modeling of intra-urban residential variability in multiple traffic-related air pollutants. Environ Health Perspect 2008, 16:7-17.

5. Clougherty JE, Kheirbek I, Eisl HM, Ross Z, Pezeshki G, Gorczynski JE, Johnson S, Markowitz S, Kass D, Matte T: Intra-urban spatial variability in wintertime street-level concentrations of multiple combustion-related air pollutants: The New York City Community Air Survey (NYCCAS). J of Expos Sci and Environ Epidemiol 2013, 23:232-240.

6. Wheeler AJ, Smith-Doiron M, Xu X, Gilbert NL, Brook JR: Intra-urban variability of air pollution in Windsor, Ontario - measurement and modeling for human exposure assessment. Environ Res 2008, 106:7-16.

7. Matte TD, Ross Z, Kheirbek I, Eisl HM, Johnson S, Gorczynski JE, Kass D, Markowitz S, Pezeshki G, Clougherty JE: Monitoring intraurban spatial patterns of multiple combustion air pollutants in New York City: Design and implementation. J of Expos Sci and Environ Epidemiol 2013, 23:223-231.

8. Briggs DJ, Collins S, Elliot P, Fischer P, Kingham S, Lebret E, Pyrl K, Van Reeuwijk H, Smallbone K, Van Der Veen A: Mapping urban air pollution using GIS: a regression-based approach. Int J Geographical Information Science 1997, 11:699-718.

9. Krewski D, Jerrett M, Burnett RT, Ma R, Hughes E, Shi Y, Turner MC, Pope CAlll, Thurston G, Calle EE, Thun MJ, Beckerman B, DeLuca P, Finkelstein N, Ito K, Moore DK, Newbold KB, Ramsay T, Ross Z, Shin H, Tempalski B: Extended Follow-up and Spatial Analysis of the American Cancer Society Study Linking Particulate Air Pollution and Mortality. Research Report. Vol. 140. Boston: Health Effects Institute; 2009.

10. Brauer M, Hoek G, Van Vliet P, Meliefste K, Fischer PH, Wijga A, Koopman LP, Neijens HJ, Gerritsen J, Kerkhof M, Heinrich J, Bellander T, Brunekreef B: Air pollution from traffic and the development of respiratory infections and asthmatic and allergic symptoms in children. Am J Respir Crit Care Med 2002, 166:1092-1098.

11. Jerrett M, Arain A, Kanraglou P, Beckerman B, Potoglou D, Sahsuvaroglu T, Morrison J, Giovis C: A review and evaluation of intraurban air pollution exposure models. J of Expos Sci and Environ Epidemiol 2005, 15:185-204.
12. Ryan PH, LeMatsers GK: A Review of Land-use Regression Models for Characterizing Intraurban Air Pollution Exposure. Inhal Toxicol 2007, 19(Suppl 1):127-133.

13. Hunte H, Bangs R, Thompson K: The Health Status of African Americans in Allegheny County: A Black Paper for the Urban League of Pittsburgh. Pittsburgh: University Center for Social and Urban Research; 2002.

14. Bush EL: Allegheny County Health in Black and White. Pittsburgh: Urban League of Greater Pittsburgh; 2011.

15. Clougherty JE, Houseman EA, Levy Jl: Source apportionment of indoor residential fine particulate matter using land use regression and constrained factor analysis. Indoor Air 2011, 21:53-66.

16. Lebret E, Briggs D, van Reeuwijk H, Fischer P, Smallbone K, Harssema H, Kriz $\mathrm{B}$, Gorynski $\mathrm{P}$, Elliott $\mathrm{P}$ : Small area variations in ambient $\mathrm{NO}_{2}$ concentrations in four European areas. Atmosph Environ 2000, 34:177-185.

17. Hoek G, Beelen R, de Hoogh K, Vienneau D, Gulliver J, Fischer P, Briggs D: A review of land-use regression models to assess spatial variation of outdoor pollution. Atmosph Environ 2008, 42:7561-7578.

18. Ross Z, Ito K, Johnson S, Yee M, Pezeshki G, Clougherty JE, Savitz D, Matte T: Spatial and temporal estimation of air pollutants in New York City: exposure assignment for use in a birth outcomes study. Environ Health 2013, 12:51-63.

19. Allegheny County Health Department: Air Quality Program: Air Quality Annual Report for 2011 with 1991-2011 Trends. Pittsburgh: Allegheny County Health Department; 2011.

20. Chu N, Kadane JB, Davidson C: Identifying likely PM2.5 sources on days of elevated concentration: a simple statistical approach. Environ Sci Technol 2009, 43:2407-2411.

21. Tang W, Raymond T, Wittig B, Davidson C, Pandis SN, Robinson AL, Crist K: Spatial Variations of $\mathrm{PM}_{2.5}$ During the Pittsburgh Air Quality Study. Aerosol Sci Technol 2004, 38(Suppl 2):80-90.

22. Wittig AE, Anderson N, Kylystov AY, Pandis SN, Davidson C, Robinson AL: Pittsburgh Air Quality Study overview. Atmosph Environ 2004, 38:3107-3125.

23. INRIX Traffic Scorecard: Worst Corridors 2011. [http://scorecard.inrix.com/ scorecard/uscorridors.asp]

24. US Census Bureau American Community Survey 2005-2009. [http://www. census.gov/acs/www/data_documentation/2009_5yr_data/]

25. Allegheny County Health Department: Revision to the Allegheny County Portion of the Pennsylvania State Implementation Plan: Attainment Demonstration for the Liberty-Clairton PM2.5 Nonattainment Area. Pittsburgh: Allegheny County Health Department; 2011.

26. Whiteman CD: Breakup of Temperature Inversions in Deep Mountain Valleys: Part I. Observations. J App/ Meteorol 1982, 21:270-289.

27. Whiteman CD, McKee TB: Air pollution implications of inversion descent in mountain valleys. Atmosph Environ 1978, 12:2151-2158.

28. Shrenk HH, Heimann H, Clayton GD, Gafafer WM, Wexler H: Air Pollution in Donora, Pennsylvania. In Bulletin 306, U.S. Public Health Service. Washington: 1949.

29. Pope CAlll, Muhlestein JB, May HT, Renlund DG, Anderson JL, Horne BD: Ischemic heart disease events triggered by short-term exposure to fine particulate air pollution. Circulation 2006, 114:2443-2448.

30. Dockery DW, Pope CA III: Acute respiratory effects of particulate air pollution. Ann Rev Pub Hlth 1994, 15:107-113.

31. Beard JD, Beck C, Graham R, Packham SC, Traphagan M, Giles R, Morgan JG: Winter Temperature Inversions and Emergency Department Visits for Asthma in Salt Lake County, Utah, 2003-2008. Environ Health Perspect 2012, 120:1385-1390.

32. Tunno BJ, Shields KN, Lioy PJ, Chu N, Kandane JB, Parmanto B, Pramana G, Zora J, Davidson C, Holguin F, Clougherty JE: Understanding Intra-Neighborhood Patterns in PM2.5 and PM10 Using Mobile Monitoring in Braddock, PA. Environ Health 2012, 11:76-90.

33. Zhu Y, Hinds WC, Kim S, Sioutas C: Concentration and size distribution of ultrafine particles near a major highway. J Air Waste Manag Assoc 2002, 52:1032-1041

34. Karner AA, Eisinger DS, Niemeier DA: Near Roadway Air Quality: Synthesizing the Findings from Real-World Data. Environ Sci Technol 2010, 44:5334-5344

35. Pennsylvania Department of Transportation: Bureau of Planning and Research, Geographic Information Division. Pennsylvania State Roads. [http://www.pasda.psu.edu]

36. US Environmental Protection Agency: National Emissions Inventory 2008. http://www.epa.gov/ttnchie1/net/2008inventory.html. 
37. Briggs DJ, de Hoogh C, Gulliver J, Wills J, Elliot P, Kingham S, Smalllbone K: A regression-based method for mapping traffic-related air pollution: application an testing in four contrasting urban environments. Sci Tot Environ 2000, 253:151-167.

38. Ross Z, English PB, Scalf R, Gunier R, Smorodinsky S, Wall S, Jerrett M: Nitrogen dioxide prediction in Southern California using land use regression modeling: Potential for environmental health analyses. J Expos Sci Environ Epidemiol 2006, 16:106-114.

39. Ryan PH, LeMasters GK, Biswas P, Levin L, Hu S, Lindsey M, Bernstein DI, Lockey J, Villareal M, Khurana Hershey GK, Grinshpun SA: A comparison of proximity and land use regression traffic exposure models and wheezing in infants. Environ Health Perspect 2007, 115:278-284.

40. Gesch DB: The National Elevation Dataset. In Digital Elevation Model Technologies and Applications: The DEM Users Manual. 2nd edition. Edited by Maune D. Bethesda, Maryland: American Society for Photogrammetry and Remote Sensing; 2007:99-118.

41. Brauer M, Hoek G, van Vliet P, Melifiefste K, Fischer P, Gehring U, Heinrich J, Cyrus J, Bellander T, Lewne M, Brunekreef B: Estimating long-term average particulate air pollution concentrations: application of traffic indicators and geographic information systems. Epidemiology 2003, 14:228-239.

42. Madsen C, Lødrup Carlsen KC, Hoek G, Oftedal B, Nafstad P, Meliefste K, Jacobsen R, Nystad W, Carlsen K, Brunekreef B: Modeling the intra-urban variability of outdoor traffic pollution in Oslo, Norway - a GA ${ }^{2}$ LEN project. Atmosph Environ 2007, 41:7500-7511.

43. Milionis AE, Davies TD: Association between atmospheric temperature inversions and vertical wind profiles: a preliminary assessment. Meteorol Appl 2002, 9:223-228.

44. Levy I, Mihele C, Lu G, Narayan J, Hilker N, Brook JR: Elucidating multipollutant exposure across a complex metropolitan area by systematic deployment of a mobile laboratory. Atmos Chem Phys Discuss 2012, 12:31585-31627.

45. Wallace J, Corr D, Kanaroglou P: Topographic and spatial impacts of temperature inversions on air quality using mobile pollution surveys. Sci Tot Environ 2010, 408:5086-5096.

46. Wallace J, Kanaroglou P: The effect of temperature inversions on ground-level nitrogen dioxide $\left(\mathrm{NO}_{2}\right)$ and fine particulate matter (PM2.5) using temperature profiles from the Atmospheric Infrared Sounder (AIRS). Sci Tot Environ 2009, 407:5058-5095

47. Nkemdirim LC: Cold air drainage and temperature fields in an urban environment. Atmosph Environ 1980, 14:375-381.

48. Kuttler W, Barlag A-B, Robmann F: Study of the thermal structure of a town in a narrow valley. Atmosph Environ 1996, 30:365-378.

49. Eeftens M, Beelen R, de Hoogh K, Bellander T, Cesaroni G, Cirach M, Dédelè A, Dons E, de Nazelle A, Dimakopoulou K, Eriksen K, Falq G, Fischer P, Galassi C, Gražulevičienè R, Heinrich J, Hoffmann B, Jerrett M, Keidel D, Korek M, Lanki T, Lindley S, Madsen C, Mölter A, Nádor G, Nieuwenhuijsen M, Nonnemacher M, Pedelli X, Raaschou-Nielsen O: Development of land use regression models for PM (2.5), PM (2.5) absorbance, PM (10) and PM (coarse) in 20 European Study Areas; Results of the ESCAPE Project. Environ Sci Technol 2012, 46:11195-11205.

doi:10.1186/1476-069X-13-28

Cite this article as: Shmool et al:: Saturation sampling for spatial variation in multiple air pollutants across an inversion-prone metropolitan area of complex terrain. Environmental Health 2014 13:28.

\section{Submit your next manuscript to BioMed Central and take full advantage of:}

- Convenient online submission

- Thorough peer review

- No space constraints or color figure charges

- Immediate publication on acceptance

- Inclusion in PubMed, CAS, Scopus and Google Scholar

- Research which is freely available for redistribution

Submit your manuscript at www.biomedcentral.com/submit 